\title{
A Comparative Study of Cardiovascular Response and Analgesic Effects of Bupivacaine and Butorphanol
}

\author{
Keshava Murthy MR ${ }^{1}$, Vikas $\mathrm{KN}^{2}$ \\ ${ }^{1}$ Assistant Professor, Department of Emergency Medicine, Ramaiah Medical College, ${ }^{2}$ Assistant Professor, Department of Anaesthesiology, Ramaiah \\ Medical College.
}

\section{Abstract}

Background: Several methods have been used to relieve post-operative pain, among which epidural administration of local anaesthetic and opioids gained popularity. While proving analgesia through epidural route, cardiovascular response of epidural administered $0.25 \%$ bupivacaine with $2 \mathrm{mg}$ butorphanol. Subjects and Methods: 50 patients between 40-50 years of age undergoing hysterectomy randomly allotted to 2 groups of 25 patients in each group. Group I received $10 \mathrm{ml}$ of $0.25 \%$ Bupivacaine and Group II received 2 mg Butorphanol diluted in $18 \mathrm{ml}$ of normal saline via epidural placed catheter before giving General Anaesthesia for performing hysterectomy. The general anaesthesia technique was the same in both groups of patients. Cardiovascular responses like heart rate, systolic blood pressure, diastolic blood pressure and mean arterial pressure were monitored post-operatively for $10 \mathrm{hrs}$. Onset of analgesia, duration of analgesia and side effects like nausea, vomiting and sedation were also noted. Results: Heart rate were similar between 2 groups before and after injection of drugs into the epidural space $(\mathrm{P}>0.05)$. There was decrease in the mean systolic blood pressure $(\mathrm{P}<0.05)$, mean diastolic blood pressure $(\mathrm{P}<0.001)$ and mean arterial pressure $(\mathrm{P}<0.001)$ in group I. Onset of analgesia was faster with butorphanol(11.76 minutes) when compared to Bupivacaine $(14.38$ minutes $)$ and duration of analgesia was longer with butorphanol(7.48 minutes) when compared with Bupivacaine(6.67 minutes). Side effects like nausea, vomiting were more with Bupivacaine (20\%) and sedation was the main side effect with butorphanol (40\%). Conclusion: Our study concludes that epidural administration $10 \mathrm{ml}$ of $0.25 \%$ Bupivacaine causes significant hypotension when compared to $2 \mathrm{mg}$ Butorphanol with $8 \mathrm{ml}$ of normal saline given epidural. Butorphanol in epidural space has quicker and longer analgesic action than $0.25 \%$ bupivacaine.

Keywords: Cardiovascular Response, Epidural Anagesia, Bupivacaine and Butorphanol

Corresponding Author: Dr. Vikas KN, Assistant Professor, Department of Anaesthesiology, Ramaiah Medical College.

Received: December 2019

Accepted: December 2019

\section{Introduction}

Post-operative pain is an acute form of pain which start with surgical trauma and ends with surgical healing. Despite advances in the knowledge, skill and understanding of pain process there appears to be little improvement in the management of postoperative pain. Anaesthesiologists occupy a unique position to co-operative multi-disciplinary pain management.

Pain is not just a sensory modality but an experience. The International Association for the Study of pain defines pain as an unpleasant sensory and emotional experience associated with actual or potential tissue damage, or described in terms of such damage'. ${ }^{[1]}$ The response to pain is highly variable between persons as well as in the same person at different times. ${ }^{[2]}$ The relation between quality of analgesia and post-operative outcome remains ill defined. In numerous studies have perioperative physiologic responses in addition to pain relief.

In controlling post-operative pain several methods are adopted of which epidural analgesia gained much popularity because it improves the cardio respiratory function. Several drugs are used in the epidural space.
Use of local anaesthetics like Bupivacaine \& opioids like Butorphanol are established for its analgesic property. In the enthusiasm of providing good analgesia in a postoperative patient, sometimes it can result in Cardiovascular collapse if the volume status of the patient is compromised. Central neuraxial blockade is associated with physiological reposes mainly variation in heart rate and cardiac contractility which results from decreased sympathetic tone and unopposed parasympathetic tone. ${ }^{[3]}$ These physiological responses are more pronounced when bupivacaine was used. Bupivacaine has acquired a reputation for slower onset and hence it would seem attractive to use an agent having the characteristics of faster onset while still retaining the desirable long duration of action of bupivacaine. ${ }^{[4,5]}$

Butorphanol, a synthetic agonist-antagonist analgesic is effective in relieving pain when used epidural. Butorphanol is considered for its excellent analgesia and cardiovascular stability. ${ }^{[4,5]}$

\section{Aims and Objectives}

1. To study the cardiovascular response of epidurally administered $10 \mathrm{ml}$ of $0.25 \%$ bupivacaine or $2 \mathrm{mg}$ butorphanol in providing postoperative analgesia in 
patients for hysterectomies under the same technique of general anaesthesia.

2. To compare the onset, duration and quality of pain relief among patients who received epidural $10 \mathrm{ml}$ of $0.25 \%$ bupivacaine or $2 \mathrm{mg}$ of butorphanol as method of postoperative pain therapy.

3. To find out this of these drug causes significant hypotension following administration into the epidural space

\section{Subjects and Methods}

Fifty patients of ASA class 1 and 2, posts for Hysterectomy selected for the study after obtaining ethical committee clearance, institutional approval and informed consent from the patients. Patients were randomly divided into two groups of 25 each.

Group I- Receiving $10 \mathrm{ml}$ of $0.25 \%$ of Bupivacaine.

Group II- Receiving 2mg Butorphanol diluted with $8 \mathrm{ml}$ saline.

\section{Inclusion criteria:}

- ASA physical status class 1 and 2

- Both abdominal \& vaginal Hysterectomies

- Age between 40 and 50 Years

\section{Exclusion criteria:}

- Emergency surgeries

- Severe anaemia, coagulation abnormalities and bleeding disorders.

- Patients with previous history of spine surgeries

- Patients with spinal deformity

- Patients with history of chronic backache

- Patients with active skin lesions over the lumbosacral area.

- Patients with IHD, valvular diseases, COPD, bronchial asthma.

A through pre-anaesthetic evaluation was done Tab Diazepam 5-10mg orally was given on the previous night. Patients were kept nil orally for $8 \mathrm{hrs}$ before surgery.

On the day of surgery premedication was given using inj. Pethidine $1.5 \mathrm{mg} / \mathrm{kg} \& \mathrm{inj}$. Promethazine $0.5 \mathrm{mg} / \mathrm{kg}$ intramuscularly 90 minutes before induction of Anaesthesia. After shifting the patient to the operation table, monitors were connected and patient was positioned in right or left lateral or sitting position. Under aseptic precautions, L2-L3 or L3-L4 interspace was identified and skin was infiltrated with injection of local anaesthetics.

Epidural space approached with $16 \mathrm{G}$ or $18 \mathrm{G}$ Tuohy needle using loss of resistance technique with air. Then $16 \mathrm{G}$ or $18 \mathrm{G}$ epidural catheter was passed through the needle till about 4-6 $\mathrm{cms}$ of the catheter is in the space. The needle was withdrawn and catheter fixed to the back.

$3 \mathrm{ml}$ of $2 \%$ lignocaine with adrenaline 1:2,00,000 was injected through the catheter as a test dose to rule out intravascular / intrathecal placement of the catheter.

General Anaesthesia was administered to all patients using same kind of drugs and techniques to perform hysterectomy. After the surgery patients were shifted to postoperative care area and monitoring was done. Those patients who had variable cardiovascular parameters were corrected by oxygen $\&$ fluid therapy. When the patients first complained of pain, they were shown Visual Analogue Scale (VAS) to express the intensity of pain on the scale. When it reached 6 mark on the scale, patients were given the following drugs through the epidural catheter according to their group.

Group 1- $10 \mathrm{ml}$ of $0.25 \%$ of Bupivacaine.

Group 2- 2mg Butorphanol diluted with $8 \mathrm{ml}$ saline.

Visual Analogue Scale (VAS) was used to assess the intensity of pain and pain relief at regular intervals. Onset of analgesia is time interval from drug administration till VAS score come down to 2. Duration of analgesia is time interval between the onset, till patient complaints of pain (VAS $\geq 6$ ) when rescue analgesia was given - the end point of her participation in the study. The following parameters were recorded hourly till $12 \mathrm{hrs}$ Onset of analgesia. Duration of analgesia Cardio vascular monitoring: Pulse rate, systolic, diastolic and mean arterial pressure. Side effects: Nausea/vomiting, pruritus, sedation, shivering, seizures. All the observations and particulars of each patient were recorded

\section{Statistical Methods:}

Student $t$ test/ Chi-square test have been used to find the significance of homogeneity of study characteristics between two groups of patients.

Student t test (Unpaired, two tailed) has been used to find the significance of hemodynamic between two groups.

Chi-square / Fisher Exact test has been used to find out the significance of incidence of nausea and vomiting between two group of patients.

\section{Significant figures}

$\mathrm{P}>0.05$ statistically insignificant

$P<0.05$ statistically significant

$P<0.01$ statistically highly significant

$\mathrm{P}<0.001$ statistically very highly significant.

\section{Results}

Present study was conducted on fifty adult patients in ASA class $1 \& 2$ aged between $40-50$ years, weighing 40 to $60 \mathrm{kgs}$. A prospective randomized comparative study was undertaken to evaluate and compare the cardiovascular response in patients divided into 2 groups of 25 each. Group I received $10 \mathrm{ml}$ of $0.25 \%$ bupivacaine epidurally and Group II received $2 \mathrm{mg}$ of butorphanol diluted with $8 \mathrm{ml}$ of normal scale epidurally.

Table 1: Demographic Data
\begin{tabular}{|l|l|l|l|}
\hline & Group I & Group II & P value \\
\hline Age in years & $44.32 \pm 2.04$ & $43.92 \pm 2.53$ & 0.541 \\
\hline $\begin{array}{l}\text { Weight in } \\
\text { kg }\end{array}$ & 51.67 & $51-60$ & 0.747 \\
\hline
\end{tabular}

Table 2: Type of Surgery
\begin{tabular}{|l|l|l|l|}
\hline Type of surgery & Group I & Group II & P value \\
\hline TAH & $15(60.0 \%)$ & $17(68.0 \%)$ & 0.558 \\
\hline VH & $10(40.0 \%)$ & $8(32.0 \%)$ & \\
\hline
\end{tabular}

The two groups were comparable with respect to age, weight, and Type of surgery 
Table 3: Comparison of Mean Heart Rate [Bpm]

\begin{tabular}{|l|l|l|l|l|l|}
\hline \multirow{2}{*}{ Study period } & Group I & Group II & \multirow{2}{*}{ P value } \\
\cline { 2 - 5 } & Mean & SD $( \pm)$ & Mean & SD $( \pm)$ & \\
\hline Pre-injection & 79.92 & 3.43 & 81.48 & 3.71 & 0.129 \\
\hline Post - Injection period & 80.40 & 3.97 & 80.68 & 3.69 & 0.797 \\
\hline 5 minute & 81.36 & 4.63 & 80.60 & 3.82 & 0.529 \\
\hline 10 minute & 83.16 & 3.47 & 81.92 & 3.23 & 0.197 \\
\hline 15 minute & 82.56 & 3.81 & 82.60 & 3.01 & 0.967 \\
\hline 30 minute & 80.68 & 3.59 & 82.12 & 3.27 & 0.145 \\
\hline 1 hour & 80.72 & 3.48 & 81.68 & 3.22 & 0.317 \\
\hline 2 hour & 80.72 & 3.68 & 81.68 & 3.75 & 0.365 \\
\hline 4 hour & 78.92 & 3.05 & 80.48 & 3.00 & $0.075+$ \\
\hline 6 hour & 81.64 & 3.53 & 80.84 & 3.33 & 0.414 \\
\hline 8 hour & 79.92 & 3.43 & 81.48 & 3.71 & 0.129 \\
\hline 10 hour & \multicolumn{5}{|l|}{} \\
\hline
\end{tabular}

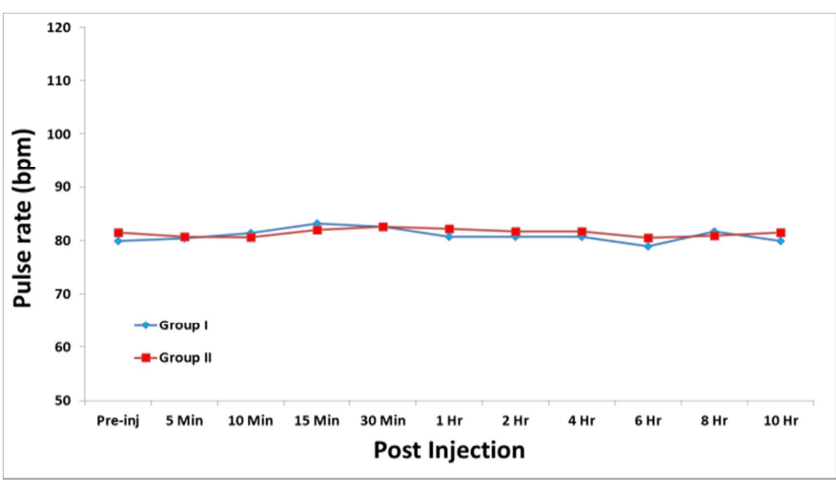

Figure 1: Comparison of Mean Heart Rate [bpm]

Heart rate was similar between two groups before \& after injection of drugs into the epidural space. The groups were comparable as $\mathrm{P} \geq 0.05$

Table 4: Comparison of Mean Systolic Blood pressure[mm Hg]

\begin{tabular}{|c|c|c|c|c|c|}
\hline \multirow[t]{2}{*}{ Study period } & \multicolumn{2}{|l|}{ Group I } & \multicolumn{2}{|c|}{ Group II } & \multirow[t]{2}{*}{ P value } \\
\hline & Mean & $\operatorname{SD}( \pm)$ & Mean & $\mathbf{S D}( \pm)$ & \\
\hline Pre-injection & 136.84 & 3.52 & 136.52 & 4.51 & 0.781 \\
\hline \multicolumn{6}{|c|}{ Post - Injection period } \\
\hline 5 minute & 130.48 & 3.83 & 135.64 & 4.17 & $<0.001 * *$ \\
\hline 10 minute & 118.52 & 17.34 & 135.16 & 4.34 & $<0.001 * *$ \\
\hline 15 minute & 120.56 & 16.85 & 134.68 & 4.42 & $<0.001 * *$ \\
\hline 30 minute & 128.52 & 5.67 & 135.16 & 4.76 & $<0.001^{* * *}$ \\
\hline 1 hour & 129.72 & 4.84 & 136.24 & 3.79 & $<0.001 * *$ \\
\hline 2 hour & 131.84 & 4.74 & 135.56 & 3.65 & $0.003^{* *}$ \\
\hline 4 hour & 131.76 & 3.46 & 134.80 & 3.61 & $0.004 * *$ \\
\hline 6 hour & 132.60 & 3.42 & 132.08 & 3.50 & 0.597 \\
\hline 8 hour & 133.56 & 3.03 & 132.72 & 2.57 & 0.296 \\
\hline 10 hour & 13684 & 3.52 & 136.52 & 451 & \\
\hline
\end{tabular}

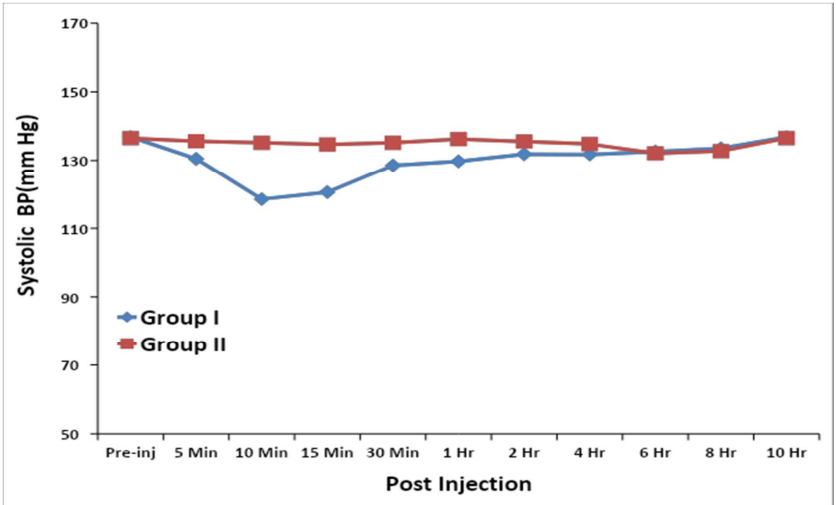

Figure 2: Comparision of Mean Systolic Blood Pressure[mm Hg]
The mean systolic BP decreased after epidural injection of bupivacaine and there was no significant change in butorphanol group. A significant decrease in mean systolic BP occurred between 5 to 15 minutes and persisted up to 4 hrs. $\mathrm{P}<0.05$ highly significant.

Table 5: Comparison of Mean Diastolic Blood pressure[mm Hg]

\begin{tabular}{|l|l|l|l|l|l|}
\hline \multirow{2}{*}{ Study period } & \multicolumn{2}{|c|}{ Group I } & \multicolumn{2}{c|}{ Group II } & \multirow{2}{*}{ P value } \\
\cline { 2 - 5 } & Mean & SD( \pm ) & Mean & SD $( \pm)$ & \\
\hline Pre-injection & 81.84 & 3.45 & 83.16 & 3.01 & 0.156 \\
\hline Post - Injection period & 80.16 & 4.33 & 82.76 & 2.52 & $0.012^{*}$ \\
\hline 5 minute & 67.92 & 14.73 & 83.56 & 3.66 & $<0.001^{* *}$ \\
\hline 10 minute & 69.04 & 13.60 & 83.20 & 3.88 & $<0.001^{* *}$ \\
\hline 15 minute & 76.28. & 4.95 & 82.92 & 3.44 & $<0.001^{* *}$ \\
\hline 30 minute & 78.12 & 3.77 & 82.64 & 3.11 & $<0.001^{* *}$ \\
\hline 1 hour & 77.60 & 4.45 & 83.48 & 2.84 & $<0.001^{* *}$ \\
\hline 2 hour & 77.24 & 3.74 & 83.48 & 2.43 & $0.058+$ \\
\hline 4 hour & 79.24 & 3.07 & 79.16 & 4.51 & 0.942 \\
\hline 6 hour & 80.44 & 2.45 & 80.92 & 2.00 & 0.452 \\
\hline 8 hour & 81.84 & 3.45 & 83.16 & 3.01 & 0.156 \\
\hline 10 hour & \multicolumn{5}{|l}{} \\
\hline
\end{tabular}

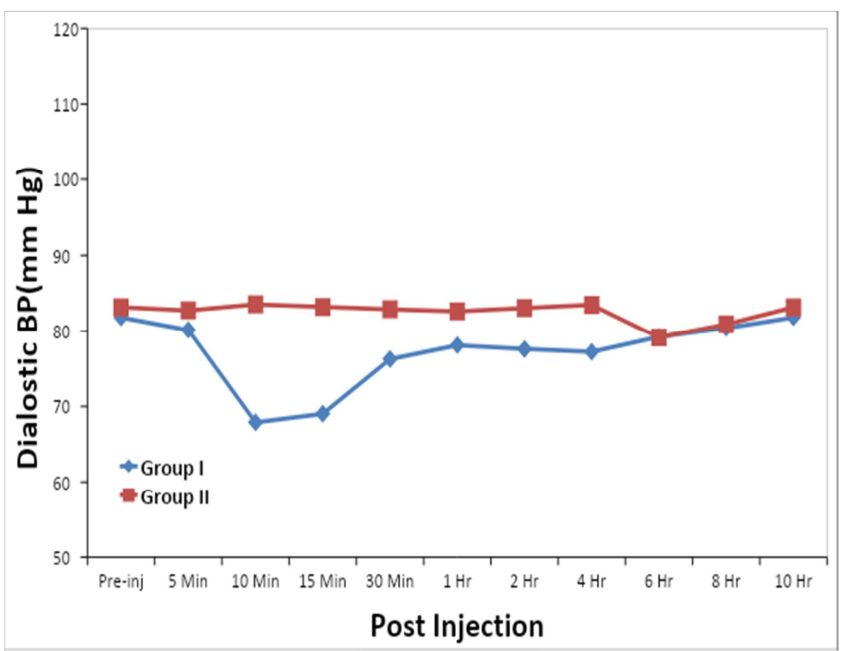

Figure 3: Comparison of Mean Diastolic Blood Pressure[mm Hg]

The mean decrease in diastolic BP seen in bupivacaine group between 5 and 15 minutes and persisted up to 2 hrs. $\mathrm{P}<0.001$ highly significant.

Table 6: Comparison of Mean arterial pressure[mm Hg]

\begin{tabular}{|c|c|c|c|c|c|}
\hline \multirow[t]{2}{*}{ Study period } & \multicolumn{2}{|c|}{ Group I } & \multicolumn{2}{|c|}{ Group II } & \multirow[t]{2}{*}{$P$ value } \\
\hline & Mean & $\mathrm{SD}( \pm)$ & Mean & $\mathrm{SD}( \pm)$ & \\
\hline Pre-injection & 99.77 & 2.95 & 100.95 & 3.24 & 0.187 \\
\hline \multicolumn{6}{|c|}{ Post - Injection period } \\
\hline 5 minute & 96.93 & 3.08 & 100.39 & 2.39 & $<0.001 * *$ \\
\hline 10 minute & 84.79 & 15.44 & 100.76 & 2.83 & $<0.001 * *$ \\
\hline 15 minute & 86.21 & 14.55 & 100.36 & 3.43 & $<0.001^{* *}$ \\
\hline 30 minute & 93.69 & 4.12 & 100.33 & 2.88 & $<0.001^{* *}$ \\
\hline 1 hour & 95.32 & 2.84 & 100.51 & 2.29 & $<0.001 * *$ \\
\hline 2 hour & 95.68 & 2.83 & 100.57 & 2.24 & $<0.001^{* *}$ \\
\hline 4 hour & 95.41 & 2.84 & 100.59 & 2.47 & $<0.001 * *$ \\
\hline 6 hour & 97.03 & 2.62 & 96.80 & 2.74 & 0.766 \\
\hline 8 hour & 98.15 & 1.75 & 98.19 & 1.39 & 0.929 \\
\hline 10 hour & 99.77 & 2.95 & 100.95 & 3.24 & \\
\hline
\end{tabular}

There was fall in mean arterial pressure in bupivacaine group between 5 to 15 minute after epidural injection and persisted up to 4 hrs $\mathrm{P}<.001$ highly significant. 


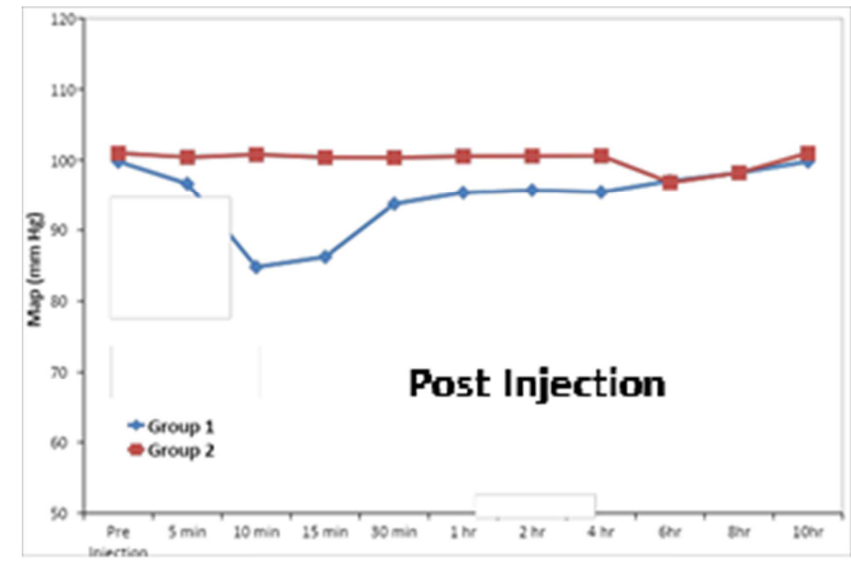

Figure 4: Comparison of Mean arterial pressure [mm Hg]

Table 7: Comparison of onset of analgesia and duration of analgesia

\begin{tabular}{|c|c|c|c|}
\hline $\begin{array}{l}\text { Onset of analgesia / } \\
\text { Duration of } \\
\text { Analgesia }\end{array}$ & Group I & Group II & P Value \\
\hline Onset of analgesia & $14.38 \pm 3.75$ & $11.76 \pm 3.54$ & \multirow[t]{2}{*}{$0.016^{*}$} \\
\hline$(\min )$ & $(10-24)$ & $(16-20)$ & \\
\hline $\begin{array}{l}\text { Duration of } \\
\text { Analgesia }\end{array}$ & $6.67 \pm 1.05$ & $7.48 \pm 1.05$ & \multirow[t]{2}{*}{$0.009^{* * *}$} \\
\hline (hrs) & $(5-8)$ & $(6-9)$ & \\
\hline
\end{tabular}

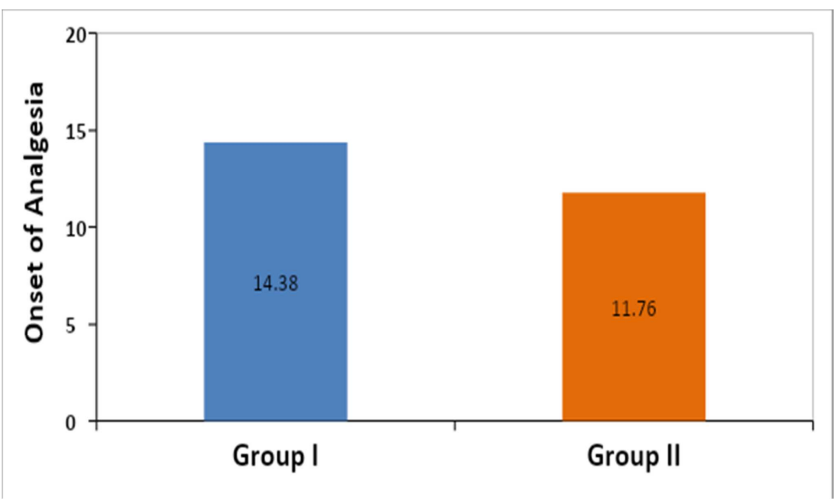

Figure 5: Onset of analgesia

Onset of analgesia with bupivacaine group occurred at 14.38 minute and with butorphanol at 11.76 minute $(\mathrm{P}<0.05)$.

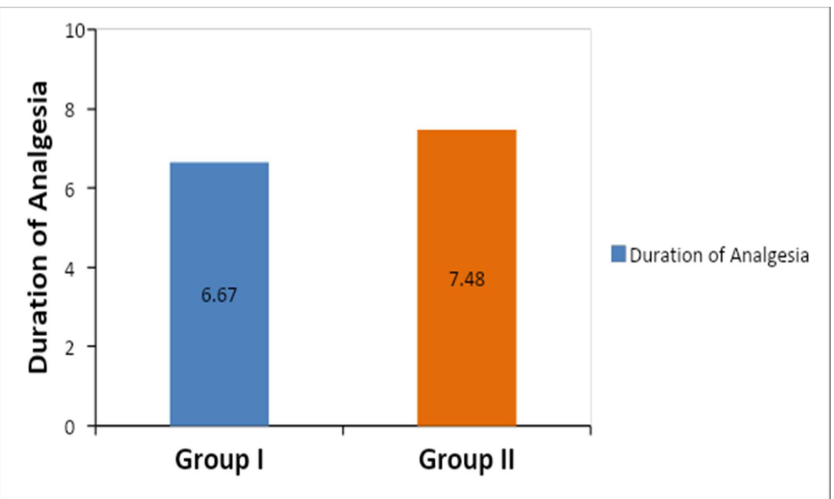

Figure 6: Duration of analgesia

Duration of analgesia with bupivacaine was 6.57 Hours and with Butorphanol for 7.48 hours $(\mathrm{P}<.01)$.
Figure 8: Comparison of side effects

\begin{tabular}{|l|l|l|l|}
\hline Side effects & Group I & Group II & P Value \\
\hline $\begin{array}{l}\text { Nausea / Vomiting } \\
\text { Sedation }\end{array}$ & 5 & 1 & 0.189 \\
& $(20.0 \%)$ & $(4.0 \%)$ & \\
& 11 & - & $<0.001 * *$ \\
\hline
\end{tabular}

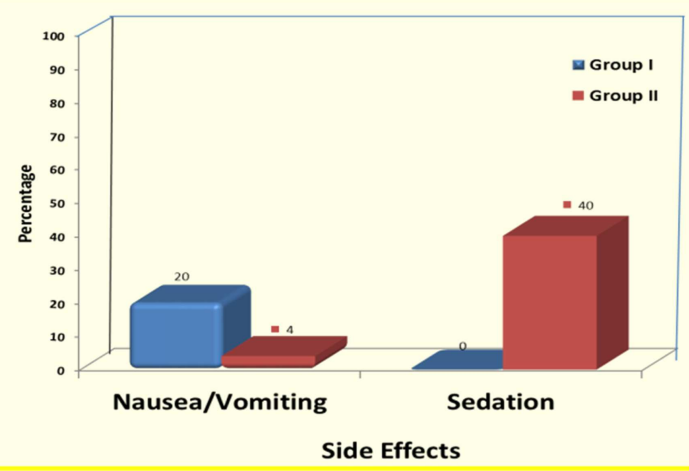

Figure 7: Comparison of side effects

Nausea/vomiting was seen in $20 \%$ of patients in bupivacaine group and $4 \%$ of Patients in butorphanol group. $\mathrm{P}>0.5$ is significant.

Sedation was seen in $40 \%$ of patients in butorphanol Group and no reported case in bupivacaine group. $\mathrm{P}<0.01$ highly significant.

\section{Discussion}

Epidural administration of local anaesthetic and opioids are practised for post-operative analgesia. The haemodynamic reposes like Hypotension \& bradycardia is known for local anaesthetics like lignocaine and bupivacaine. It is believed that opioids do not cause side effects like motor block, hypotension and bradycardia when used in the epidural space for providing analgesia. Butorphanol a new synthetic agonist - antagonist opioid drug can be used in the epidural space for providing postoperative analgesia. Only a few reports are there to highlight its advantages to use it alone or combined with local anaesthetics.

We conducted a study on 50 patients with demographic data in terms of age, weight, similar in both group. In group I we administered $10 \mathrm{ml}$ of $0.25 \%$ bupivacaine and in group II we administered $2 \mathrm{mg}$ butorphanol with $8 \mathrm{ml}$ of normal saline. There was no difference in the base line values of haemodynamic variables between the two groups.

In our study there was no difference in the mean heart rate between two groups $(\mathrm{P}>0.05)$. But when mean systolic blood pressure, mean diastolic blood pressure and mean arterial pressure were taken in to account there was a significant fall in blood pressure 5 minutes after post-operative epidural injection lasting up to 4 hours, but value assumed significance with fall of more than $20 \%$ blood pressure in bupivacaine group between 5 th minute and up to $4 \mathrm{hrs}$. When compared with butorphanol. $(\mathrm{P}<0.01)$ highly significant. Similar studies done by WD Nagan etal6, found a fall in BP in $17 \%$ of their patients. Hergert ${ }^{[7]}$ and his colleagues also experienced hypotension in their subjects who were given epidural bupivacaine. There was no case of hypotension in group II of our study. Studies 
conducted by Abbound et al, ${ }^{[8]}$ also found no episode of hypotension when butorphanol was given epidurally. Similarly there was no clinically important change in either heart rate or blood pressure when epidural butorphanol was given by Palacios and associated in their study. ${ }^{[9]}$

In our study the onset of pain relief with epidural Bupivacaine began at 14.38 minutes and action lasted for 6.67 hours. When this was compared with epidural butorphanol the action was relatively earlier which began at 11.76 minutes and lasted for 7.48 hours $\mathrm{P}<0.001$. Studies done by Zand, ${ }^{[10]}$ and colleagues using $0.5 \%$ bupivacaine epidurally had a similar onset of action which began at 17.12 minutes but duration action of action of action terminated earlier at 116.37 minutes, the discrepancy in duration of action when compared to our study is probably because this study used pin prick test to measure the maximum sensory level which is more sensitive when compared to VAS which was used in our study as it is subjective. In a study done by Mok, ${ }^{[11]}$ and his associates found that onset of pain relief with epidural butorphanol was at 15 th minute lasting for 5.4 hours. The results of this study can be compared with our study. In our study the main side effect in bupivacaine group was nausea/vomiting (20\%) but in Butorphanol group majority of patients had sedation as the main side effect. Studies done by Adooud6 and colleagues found that somnolence was predominant side effect which can be compared to our study. Our study suggests that Butorphanol can be used as an alternative to Bupivacaine with faster and longer duration of action except sedation as it predominant side effect.

\section{Conclusion}

Our study concludes that epidural administration of $10 \mathrm{ml}$ of $0.25 \%$ Bupivacaine causes significant hypotension when compared to $2 \mathrm{mg}$ of epidural Butorphanol. $2 \mathrm{mg}$ of Butorphanol in the epidural space has quicker and longer analgesic action than $10 \mathrm{ml}$ of $0.25 \%$ Bupivacaine except sedation as it main side effect.

\section{References}

1. Alan R, Aitkenhead, David J, Rowbotham, Gram smith, Management of chonic pain, Text Book of anesthesia, 4th edition Eingurgh London, Churchil living stone; 2001:738-739.

2. G.P. Dureja, Rashmi Madan, H L Kaul, Are out comes better with regional anesthesia rather than general anestheisa, Regional anesthesia and pain management current perspectives, 1st edition, New Delhi, Churchil living stone; 2002:6-19.

3. Andee Van Zundert, Gerard W. Osthime, Assessment of the epidural anesthesia, Pain relief anesthesia and in obstetrics, 1st edition, Newyork Edinburgh; churchil Living stone; 1996:267-270.

4. Charles Beattie. Opioid analegesia, goodman and Gilman's The Pharmacological Basis of Therapeutics. Joel G. Hardman, Lee E. Limbird and Alfred Goodman Gilman. 10th Edn. New York: McGraw Hill International Edition;2001, 562-629.

5. Stoelting Robert K. Opioid agonists and antagonists. Pharmacology and Physiology in anesthetic oarctice. 3rd Edn. USA: Lippincott -

6. aven; 1999, 77-79.

7. W D Ngan Kee, B B Lee, F F Ng, T K Lau, Ely Wong, K S Khaw. Randomised double - blind comparison of obstetric outcome after epidural labour analgesia using ropivacaine or bupivacaine. Hong Kong Medical Journal 2006 Apr 12(2); 45-47.

8. Hergert M, Rosolski T, Lestin HG, Stranz G. Post operative epidural analgesia current status indication and management. Anaesthesiol Reanim 2002; 27(6); 152-159

9. Abboud TK, Moore Zhu J, et al. Epidural butorphanol or morphine for the relief of post caesarean section pain: Ventilatory responses to carbon dioxide. Anesth Analg 1987; 66:887-93.

10. Quisqueya T. Palacios, Monica M. Jones, et al, Post-Caesarean section analgesia: Comparison of epidural butorphanol and morphine. Can J Anaesth 1991;338:24-50

11. F Zand, M R Razavizadeh, S Azemati, Acta medica iranica 2004; 42(4); 256-258.

12. Mok M s, Tsai Y J,et al. Efficacy of epidural butorphanol compare to morphine for the relief of post operative pain. Anestheiology 1986; 65: A 175 .

Copyright: () the author(s), publisher. Academia Anesthesiologica International is an Official Publication of "Society for Health Care \& Research Development". It is an open-access article distributed under the terms of the Creative Commons Attribution Non-Commercial License, which permits unrestricted non-commercial use, distribution, and reproduction in any medium, provided the original work is properly cited.

How to cite this article: Murthy MRK, Vikas KN. A Comparative Study of Cardiovascular Response and Analgesic Effects of Bupivacaine and Butorphanol. Acad. Anesthesiol. Int. 2019;4(2):312-16.

DOI: dx.doi.org/10.21276/aan.2019.4.2.70

Source of Support: Nil, Conflict of Interest: None declared. 